Communications in Physics, Vol. 28, No. 3 (2018), pp. 225-235

DOI:10.15625/0868-3166/28/3/12530

\title{
FORMATION OF MICRODROPLET IN T-JUNCTION MICROFLUIDIC SYSTEM: EXPERIMENT AND SIMULATION
}

\author{
NGUYEN THI THAI ${ }^{a}$, CHU THI XUAN ${ }^{a}, \dagger$, PHAM DUC THANH $^{a}$, \\ NGUYEN PHUONG NHUNG ${ }^{b}$ AND MAI ANH TUAN ${ }^{c}$ \\ ${ }^{a}$ International Institute for Materials Science, \\ Hanoi University of Science and Technology, Hanoi, Vietnam \\ ${ }^{b}$ Petro Vietnam University, \\ 672 Cach Mang Thang Tam, Long Toan Ward, Ba Ria city, Ba Ria Vung Tau Province \\ ${ }^{c}$ National Center for Technological Progress (NACENTECH), \\ 25 Le Thanh Tong, Hanoi, Vietnam \\ ${ }^{\dagger} E$-mail: xuan@itims.edu.vn
}

Received 23 April 2018

Accepted for publication 26 June 2018

Published 31 August 2018

\begin{abstract}
The purpose of this study is to investigate the formation of the water droplet in oil using T-junction microfluidic device. Both numerical and experimental methods have been implemented to investigate the dependence of droplet size versus the flow rate of two immiscible liquids as well as the system geometry. The microfluidic system was fabricated with lithography technique. The $3 D$ simulation was performed based on COMSOL software using level set method. The size of droplet is inversely proportional to the flow rate of continuous phase according to exponential function, linearly proportional with the flow rate of dispersed phase, and the width of lateral channel decrease. While the decreasing of the width of the lateral channel gives rise to the increasing of droplet velocity, the velocity of droplet depends linearly on the flow rate of disperse phase. A good consistence was observed between the theory and the experiment.
\end{abstract}

Keywords: COMSOL Multiphysics, Microdroplet, T-junction microfluidic system.

Classification numbers: 47.80.Cb, 85.40.Hp, 47.15.-x.

(C)2018 Vietnam Academy of Science and Technology 


\section{INTRODUCTION}

Droplet microfluidic with faster reaction rate, less cross-infection and reduced sample volume, has been growing strongly for two decades [1]. The microdroplets are widely applied in bio-chemical analysis and electronic microsystems $[2,3]$. Droplet-base microfluidic holds huge potential in drug discovery due to its advantages such as consuming a few microliters of sample, ability to control droplet size, and requiring only a small number of cells. Typically, aqueous samples containing biological material such as cells, DNA, bacteria, and molecules can be encapsulated into droplets.

There are common types of emulsion including oil in water (e.g. milk), and water in oil (e.g. butter). Most of cosmetic products are water in oil emulsions. It forms the base for dry/sensitive skin treatments due to its milder nature and ability to leave the skin's lipid bilayer intact. Several microfluidic geometries have been developed to synthesize uniform droplet, including T-junction geometries [4-6], flow-focusing geometries [7-9], co-flowing geometries [10-12]. T-junction microfluidic, a common structure, was first demonstrated in 2001 by Thorsen [13] in which water droplets were formed with pressure controlled laminar flow in microchannel. The authors proposed that dynamic formation of droplet is dominated by a balance of tangential shear stress and interfacial tension. Since then many studies about T-junction geometries were reported $[12,13,16,17]$. Some of them (the reports) claimed a dependence of droplet size on flow rate of two liquid [13], relative viscosity between the two phases [15], and size of the channels [14]. Several methods have been developed for simulation of droplet formation, including the fractional volume of fluid (VOF), the phase-field method, the lattice Boltzmann method (LBM), the level-set method (LSM), etc. ... Sang et al. [18] used VOF to investigate effect of viscosity on droplet formation and found a good agreement with the LBM simulation of Van der Graaf $e t$ al. [16]. The droplet size, in his report, was almost stable as the contact angle great than $165^{\circ}$. De Menech et al. [19] studied the dynamics of droplet breakup in a symmetric T-junction with low Reynolds and capillary numbers using the phase-field method. The LSM has become popular method for compressible and incompressible two-phase flow, image processing and flame propagation study. In the level set method, the interface is described by the contour of a smooth function. Here, we use a conservative level set method for two-phase flow. The fluid interface is defined by the 0.5 contour of the level set function.

In this work, a dependence of microdroplet size on flow rates of the two immiscible fluids and influence of the width of the lateral channels on the droplet formation will be discussed. PDMS-base T-junction microfluidic systems, for droplet formation, were then fabricated by photolithography technique. A T-junction model can be built using the Laminar Two-Phase Flow and Level Set interface. The model uses the predefined wetted wall boundary condition at the solid walls, with a contact angle of $135^{\circ}$.

\section{METHODS AND MATERIALS}

\section{II.1. Chemicals}

SU-8 25 was purchased from MicroChem (Newton, MA, USA), a pre-polymer solution of polydimethylsiloxane (PDMS), KE-1300T, were purchased from Shin-Etsu Chemical (Tokyo, Japan). 1, 6-Bis (acryloyloxy) hexane was purchased from Tokyo chemical industry (Japan) and poly (vinyl alcohol) was purchased from Wako Pure Chemical Industries. 


\section{II.2. Microfluidic system design}

Figure 1 illustrates the geometry of T-junction of which the uniform depth $h$, the width of center channel $w_{c}$ and lateral channel $w_{d}$ are arranged in a planar structure. Oil (as continuous phase) is pumped through the center channel with at a rate $Q_{c}$, while the dispersed-phase (water) is pushed through the lateral channel at a rate $Q_{d}$. The syringe pump was used to control the flow rate of aqueous and oil solutions. The depth of the channel $(h)$ and the width of center channel $\left(w_{c}\right)$ are fixed at $70 \mu \mathrm{m}$ and $100 \mu \mathrm{m}$, respectively. The width of the lateral was varied from $w_{d}=25$ to $100 \mu \mathrm{m}$ (Table 1).

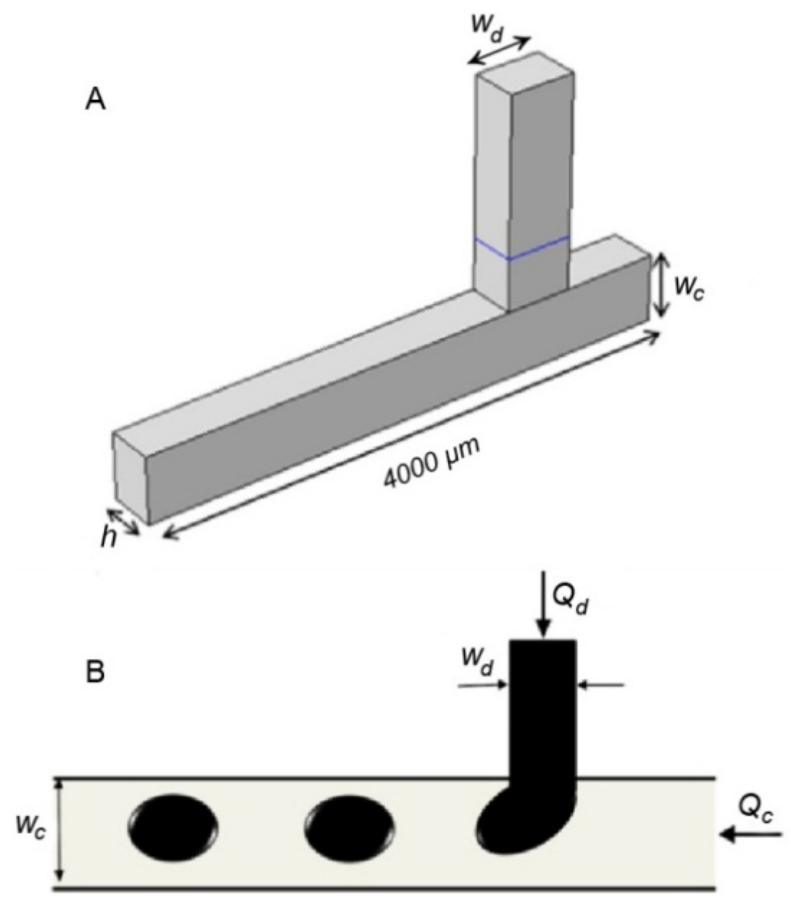

Fig. 1. A schematic of (A) three-dimensional and (B) two-dimensional of the microfluidic T-junction.

Table 1. Dimensions of the microfluidic T-junction.

\begin{tabular}{cccc}
\hline Geometry & $\boldsymbol{w}_{d}(\mu \mathbf{m})$ & $\boldsymbol{w}_{c}(\mu \mathbf{m})$ & $\boldsymbol{h}(\mu \mathbf{m})$ \\
\hline \hline $\mathbf{1}$ & 25 & 100 & 70 \\
\hline $\mathbf{2}$ & 50 & 100 & 70 \\
\hline $\mathbf{3}$ & 100 & 100 & 70 \\
\hline
\end{tabular}




\section{II.3. Fabrication of T-junction}

Photolithography techniques were used to fabricate the SU-8 mold (Fig. 2 A). The processes are below described:

Step 1: Clean the wafer ( $7.62 \mathrm{~cm}$ diameter) with $\mathrm{H}_{2} \mathrm{O}_{2}$ and $\mathrm{NH}_{3}$ solution then put it to oxygen plasma treatment.

Step 2: Spin coating SU-8 25 at $500 \mathrm{rpm}$ for $5 \mathrm{~s}$, slope $5 \mathrm{~s}$, and then $800 \mathrm{rpm}$ for $10 \mathrm{~s}$.

Step 3: Soft bake the sample at $65^{\circ} \mathrm{C}$ for $5 \mathrm{~min}$ and $95^{\circ} \mathrm{C}$ for $60 \mathrm{~min}$ then cool down for $10 \mathrm{~min}$.

Step 4: Expose the sample to UV light for $200 \mathrm{~s}$ with polarizing plate.

Step 5: Post-bake the sample at $65^{\circ} \mathrm{C}$ for $5 \mathrm{~min}$ and then $95^{\circ} \mathrm{C}$ for $10 \mathrm{~min}$.

Step 6: Develop the sample with SU-8 developer for 15 min.

Step 7: Rinse the sample with IPA and dry with nitrogen.

Step 8: Hard baking (optional).

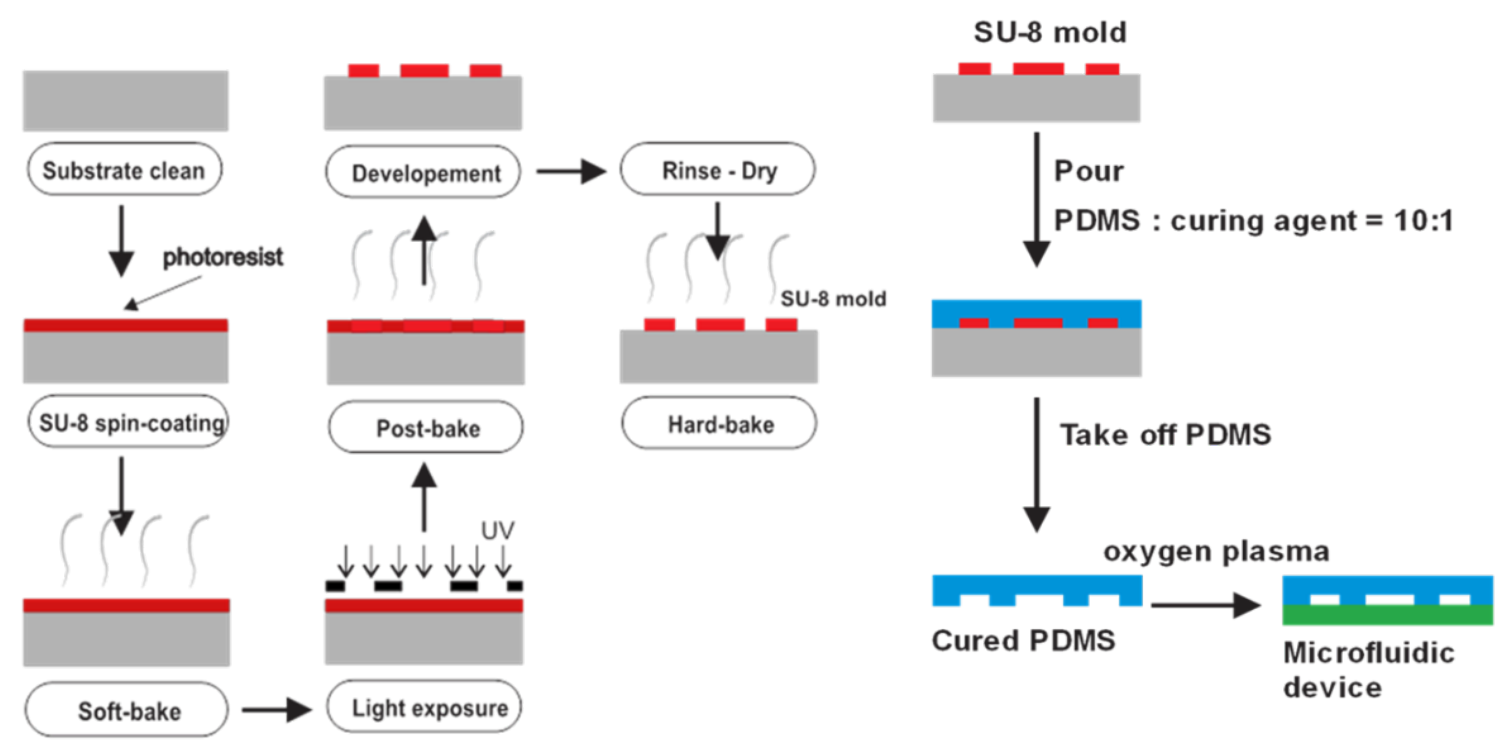

Fig. 2. The T-junction device produce process.

Fig. 2 (B) shows the process of fabrication of PDMS-base T-junction microfluidic device. T-junction channel was formed by pouring PDMS (polydimethylsiloxane) at a ratio of 10: 1 precursor to curing agent over SU-8 25 mold. The mixture solution was degassed by vacuum desiccator for $60 \mathrm{~min}$. PDMS mixture was baked at $80^{\circ} \mathrm{C}$ for $30 \mathrm{~min}$. PDMS channel and glass substrate were put into the oxygen plasma chamber in $15 \mathrm{~s}$, the pressure was $30 \mathrm{~Pa}$, and the power was $20 \mathrm{~W}$. After the plasma treatment, PDMS microchannel was bonded onto glass substrate within 1 min, followed by heating at $70^{\circ} \mathrm{C}$ in 2 hours. 


\section{II.4. Fluids Selection}

Droplet formation were conducted with a 2 wt \% poly (vinyl alcohol) aqueous solution as the to-be-dispersed phase and 1,6-Bis(acryloyloxy) hexane as the continuous phase. The physical properties of two liquids are shown in Table 2.

Table 2. Physical properties of used liquids.

\begin{tabular}{lcc}
\hline Quantity & Continuous phase & Dispersed phase \\
\hline \hline Density $\left(\mathbf{k g} / \mathbf{m}^{3}\right)$ & $1 \times 10^{3}$ & $1.02 \times 10^{3}$ \\
\hline Dynamic viscosity (Pa.s) & $6.71 \times 10^{-3}$ & $1.95 \times 10^{-3}$ \\
\hline
\end{tabular}

\section{II.5. Experimental setups}

Both dispersed and continuous phases were pumped from gas-tight syringe (MDN-0100, $1.0 \mathrm{ml})$ through the tube connect to the inlets. The flow rate of fluids is controlled by syringe pumps (BS-MD1020, AS ONE). An optical microscope (IX73, Olympus Optical Co. Ltd., Japan) equipped with a CCD camera (Watec, Japan) was used to observe the droplet formation at the T-junction. The length of droplet was measured by counting pixels.

\section{II.6. Simulation method}

The key equations for the dynamics in the current problem [20] are the incompressible Navier-Stokes (1), continuity (2), and level set equation (3):

$$
\begin{gathered}
\rho \frac{\partial u}{\partial t}+\rho(u \cdot \nabla) u=\nabla \cdot\left[-p I+\mu\left(\nabla u+(\nabla u)^{T}\right)\right]+F_{s t}, \\
\nabla u=0, \\
\frac{\partial \phi}{\partial t}+u \cdot \nabla \phi=\gamma \nabla \cdot\left(-\phi(1-\phi) \frac{\nabla \phi}{|\nabla \phi|}+\varepsilon \nabla \phi\right)
\end{gathered}
$$

where $\rho$ denotes density $\left(\mathrm{kg} / \mathrm{m}^{3}\right), u$ is velocity $(\mathrm{m} / \mathrm{s}), t$ is time (s), $I$ is the identity matrix, $\mu$ is dynamic viscosity $(\mathrm{Pa} \cdot \mathrm{s}), p$ is pressure $(\mathrm{Pa})$, and $F_{s t}$ is the surface tension force acting on the interface between two fluids $\left(\mathrm{N} / \mathrm{m}^{3}\right) ; \gamma$ and $\varepsilon$ are numerical stabilization parameters. The parameter $\varepsilon$, for determining thickness of the interface is constant in the total domain. The parameter $\gamma$ is reinitialization of the level set function and it keeps the interface thickness constant.

The effective diameter of droplet can be obtained using the following expression:

$$
d_{e f f}=2 \sqrt[3]{\frac{3}{4 \pi} \int_{\Omega} d \Omega}
$$

where $d_{\text {eff }}$ is the effective diameter of droplet, $\Omega$ represents the left most part of the horizontal channel. 


\section{RESULTS}

\section{III.1. Fabrication of T-junction microfluidic devices}

Figure 3 is a scanning electronic microscopic image of micro channel on PDMS. The shape of the fabricated T-junction is confirmed to be matched with design. The depth and width of channels' edges are clear, and sharp without any significant defect.

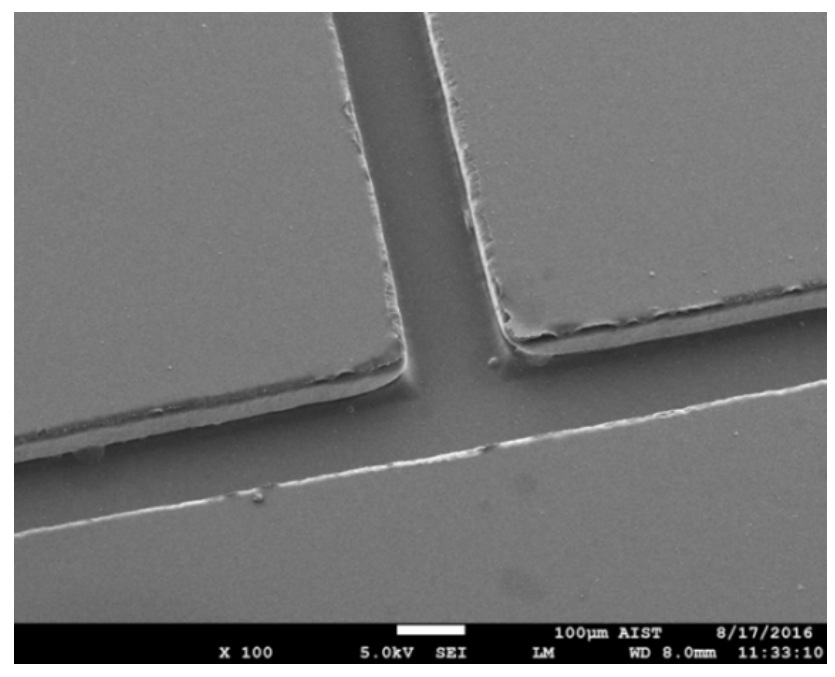

Fig. 3. SEM image of PDMS T-junction channel.

The PDMS channels were bonded onto glass through plasma oxygenated surface. The channel leakage was tested by pumping a colored liquid sample through channel under pressure of $2 \mathrm{~atm}$. As seen in Fig. 4 no liquid leakage is observed and the device was ready for droplet formation.

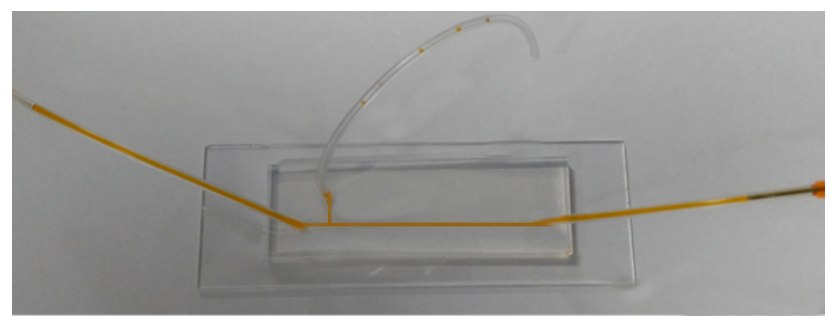

Fig. 4. Test the bonding between PDMS channel and glass substrate.

\section{III.2. Droplet formation in T-junction}

This process was performed in a rectangular T-junction microfluidic channel. Simulation results are compared with experiment results obtained for the same geometry of the channel. The snapshots of droplet formation are illustrated in Fig. 5. The flow rate of the continuous phase and the dispersed phase were set $4(\mu \mathrm{L} / \mathrm{min})$ and $1(\mu \mathrm{L} / \mathrm{min})$ respectively. At 0.07 second, the 
water droplet was developed but partly attached to bounding-edge of channel, Fig. 5 (A) and stretched out the bounding edge to form a semi-droplet shape at 0.09 second under the pressure of continuous (phase) current, Fig. 5 (B) and then released into lateral channel at 0.11 second, Fig. 5 (C). A new formation circle was restarted after removal of droplet. The observed length of droplet is a bit longer than that in simulation results. It can be explained by an oil adsorption in PDMS that narrows PDMS channel and flattened droplet [21].

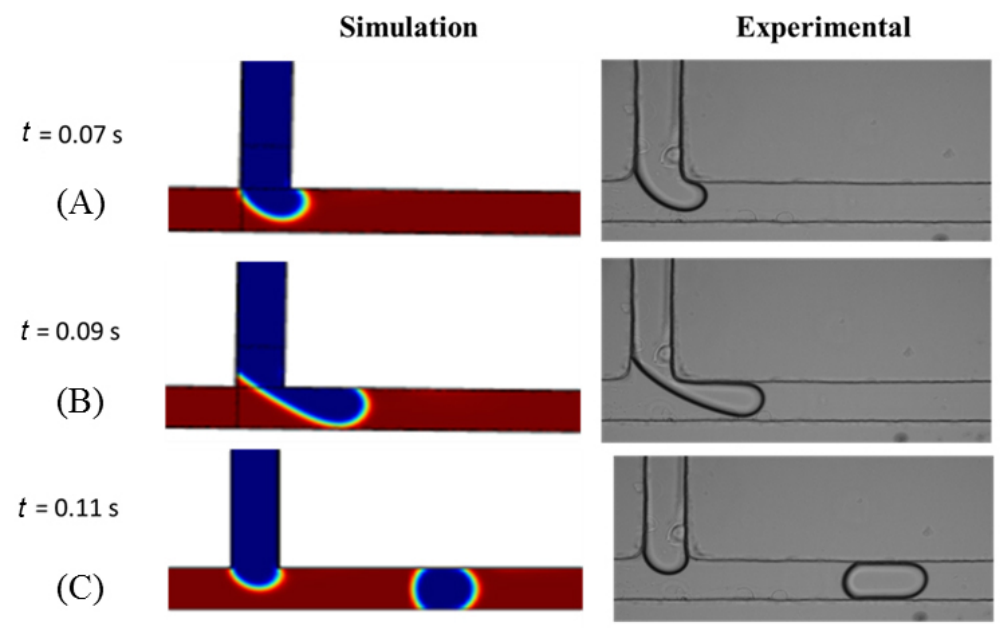

Fig. 5. Snapshots of droplet formation at a T-junction.

The channel size: $w_{d}=100 \mu \mathrm{m} ; w_{c}=100 \mu \mathrm{m}$ and $h=70 \mu \mathrm{m}$.

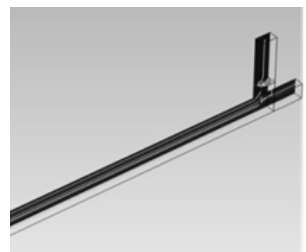

(A) $t=0.005 \mathrm{~s}$

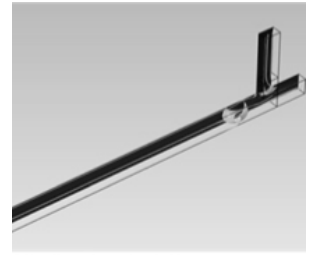

(D) $t=0.095 \mathrm{~s}$

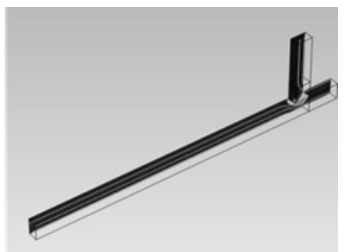

(B) $t=0.06 \mathrm{~s}$

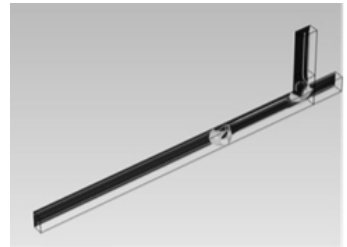

(E) $t=0.12 \mathrm{~s}$

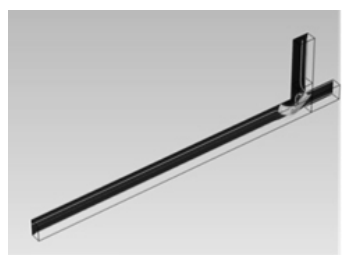

(C) $t=0.08 \mathrm{~s}$

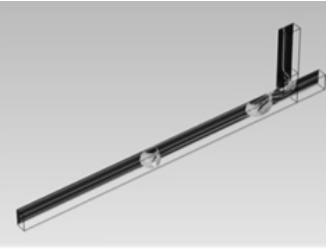

(F) $t=0.145 \mathrm{~s}$

Fig. 6. The three-dimensional process of droplet generation.

Fig. 6 illustrates the three-dimensional process of droplet generation. At $t=0.06$ second, dispersed phase began to penetrate main channel, Fig. 6 (B), then the water droplet is stretched 
out to form a semi-droplet shape at 0.08 second, Fig. $6(\mathrm{C})$. A completed droplet was formed and released into the channel at 0.095 second, Fig. 6 (D). Then a new cycle was repeated, Fig. 6 (F).

\section{III.3. Dependence of droplet size on the flow rate of channel and system geometry}

At fixed $Q_{c}=4 \mu \mathrm{L} / \mathrm{min}$, droplet size exhibited a linear dependence with the flow rate of dispersed phase $\left(Q_{d}\right)$ as $Q_{d}$ varies from 0.5 to $5 \mu \mathrm{L} / \mathrm{min}$, in both simulation, Fig. 7 (A), and experimental results, Fig. 7 (B). The dependence of the droplet length on the fixed oil flow rate $\left(Q_{d}=3 \mu \mathrm{L} / \mathrm{min}\right)$ is presented in Fig. 7 (C,D). The size of droplet is inversely proportional to the flow rate of oil by exponential function. The same range of obtained droplet length as well as dependent tendency of the droplet length on the flow rates of continuous and dispersed phases were found in previously publication of Garstecki et al [14].
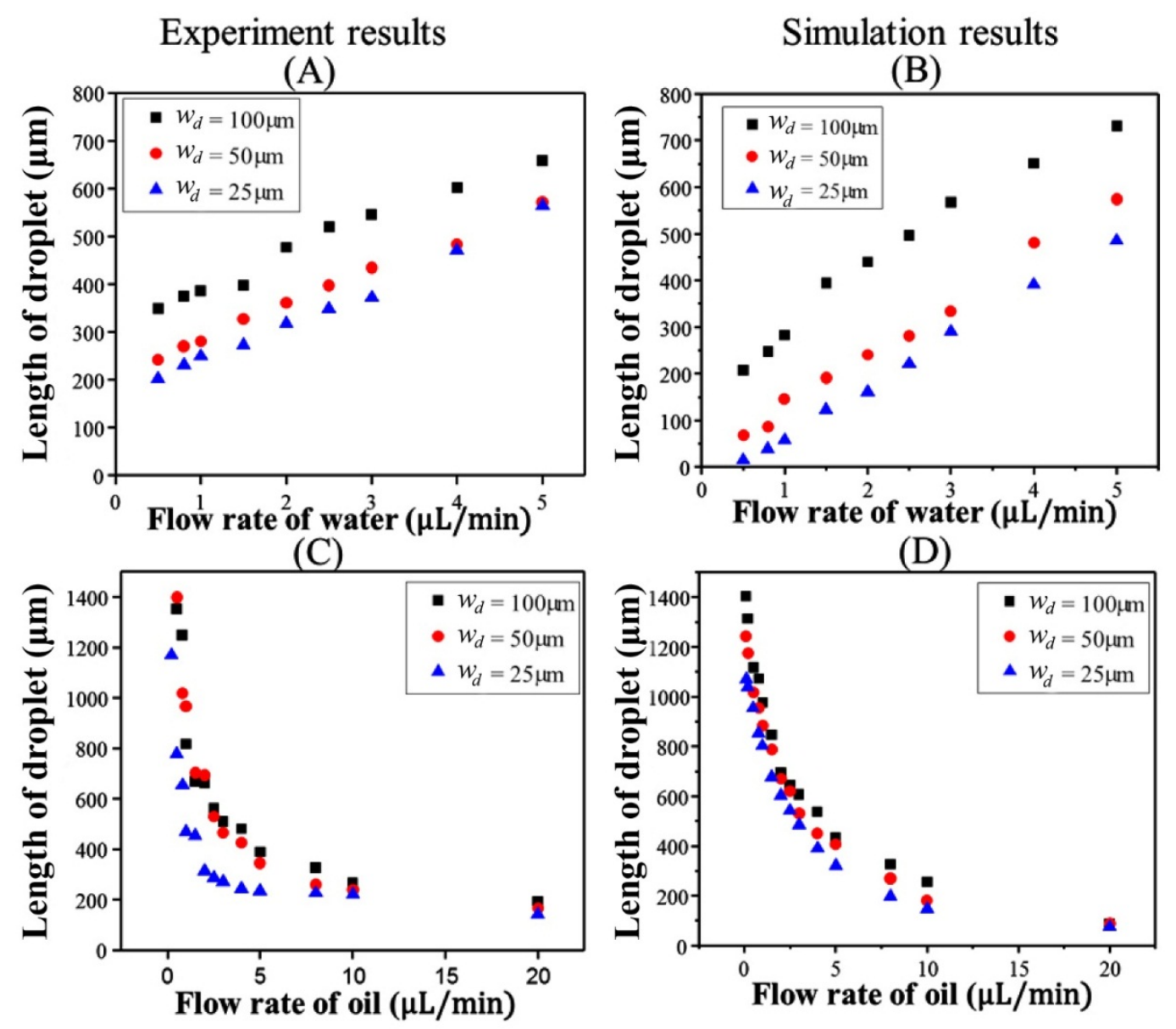

Fig. 7. Dependence of droplet length on flow rate and T-junction size.

Similarly, the flow rate of liquid in each channel was fixed while changing channel size. The dependence of droplets' lengths on channel size as well as flow rate of channels is depicted 
in Fig. 7. From the observation results, the droplet size was closely proportional to the width of lateral channel. When $Q_{c}$ is kept constant, droplet size is first order and linear function of the flow rate, Fig. 7 (A,B). In case, one fixed $Q_{d}$, such relation is non-linear, Fig. 7 (C,D). Figure 7 also exhibits that the size of formed droplet is inversely proportional with the width of lateral channels.

We can see that, simulation results (Fig. 7 (B,D)) have the same rules as the experimental results (Fig. 7 (A,C)). This confirms that the experimental results obtained are reliable and the theoretical model used in simulation is suitable in this experiment. These results are very important in system design to fabricate desired microdroplets. A diverse range in size of the droplets (100 to $1400 \mu \mathrm{m}$ in length) makes this technique advantage in applications from cell to drug encapsulation. This study is an initial step for us to conduct further research, as for example, in drug release study, a medicine is encapsulated by a solid membrane. The drug release depends on the size of the droplet and membrane properties.

\section{III.4. Velocity of droplets}

Droplet velocity was calculated by analyzing consecutive images of the droplets passing through the T-junction channel. The droplet displacement between each sequent image pair was computed, as shown in Fig. 8. The velocity of droplet was calculated using the following expression:

$$
v_{\text {droplet }}=\frac{\Delta x}{t_{2}-t_{1}}
$$

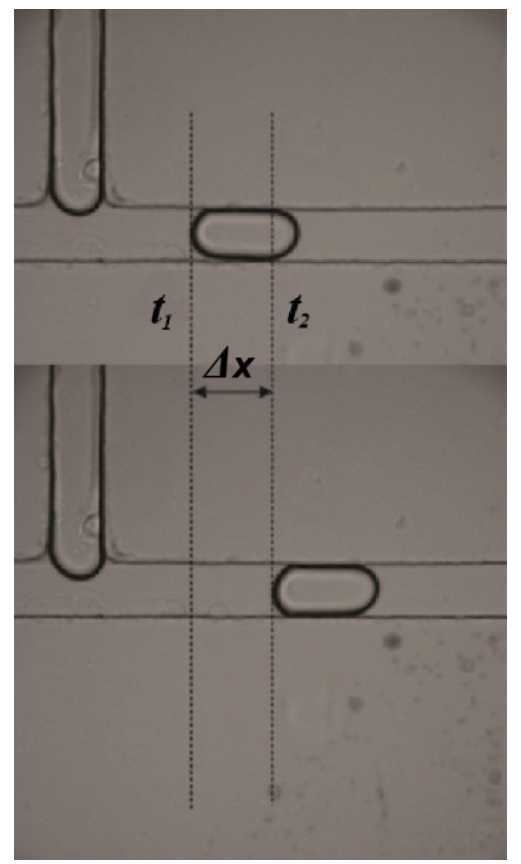

Fig. 8. Calculation of droplet velocity. 

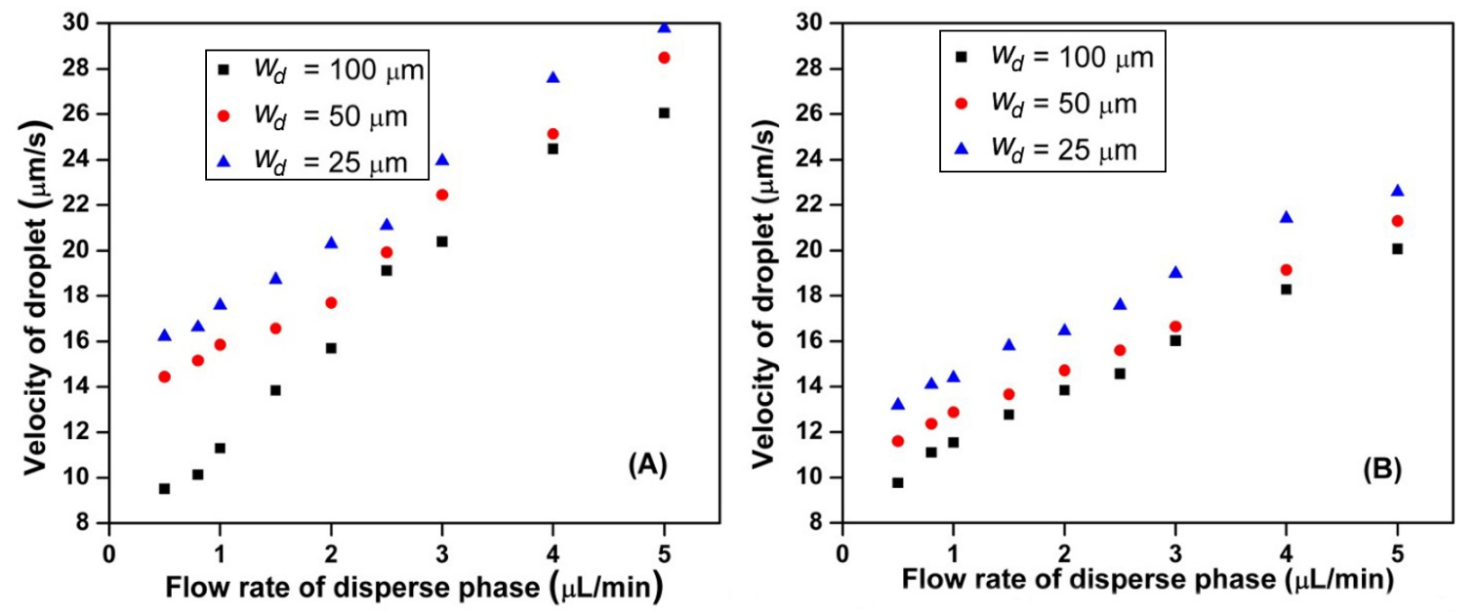

Fig. 9. Droplet velocity in T-junction (A) experiment, (B) simulation.

As shown in Fig. 9, the velocity of droplet increases with the flow rate of dispersed phase and the width of lateral channel in both experiment and simulation that matches well with Bernoulli's principle.

\section{CONCLUSION}

Formation of microdroplet in T-junction microfluidic system has been studied in both experiment and simulation. PDMS-based microfluidic systems were fabricated using photolithography and soft lithography. The simulation of the formation in T-junction channel of water droplet in oil have been carried by using a level set method. A nice matching between theoretical calculation and empirical result confirmed a right simulation model for droplet formation. The droplet size varies from $100 \mu \mathrm{m}$ to $1400 \mu \mathrm{m}$. The droplet size increases linearly with the flow rate of dispersed phase $\left(Q_{d}\right)$ and decreases according to the exponential function with the continuous phase rate $\left(Q_{c}\right)$. Similarly, when the width of the lateral channel increases, size of the droplet fabricated increases. While the width of lateral channel is proportional inversely to the droplet velocity, the velocity of droplet exhibited a linear dependence on the flow rate of disperse phase. These results are very important to fabricate microdroplets on-demand with high precision. In addition, control of droplet size is first requirement to fabricate microcapsules that encapsulate biological materials or drug, a very hot topic in both research and applications.

\section{ACKNOWLEDGMENT}

This research is funded by Vietnam National Foundation for Science and Technology Development (NAFOSTED) under grant number 103.02-2015.44.

\section{REFERENCES}

[1] G. M. Whitesides, Nature 442 (7101) (2006) 368.

[2] G. T. Vladisavljeviæ, I. Kobayashi and M. Nakajima, Microfluid. Nanofluidics 13 (1) (2012) 151.

[3] S. Duraiswamy and S. A. Khan, Small 5 (24) (2009) 2828. 
[4] S. Vandergraaf, M. Steegmans, R. Vandersman, C. Schroen and R. Boom, Colloids Surfaces A Physicochem. Eng. Asp. 266 (2005) 106.

[5] A. Gupta and R. Kumar, Phys. Fluids 22 (2010) 122001.

[6] P. Guillot and A. Colin, Phys. Rev. E 72 (6) (2005) 66301.

[7] Z. Nie, M. Seo, S. Xu, P. C. Lewis, M. Mok, E. Kumacheva, G. M. Whitesides, P. Garstecki, and H. A. Stone, Microfluid. Nanofluidics 5 (2008) 585.

[8] P. A. Romero and A. R. Abate, Lab Chip 12 (24) (2012) 5130.

[9] S. L. Anna and H. C. Mayer, Phys. Fluids 18 (12) (2006) 121512.

[10] C. Cramer, P. Fischer and E. J. Windhab, Chem. Eng. Sci. 59 (2004) 3045.

[11] A. S. Utada, Science 308 (5721) (2005) 537.

[12] P. B. Umbanhowar, V. Prasad and D. A. Weitz, Langmuir 16 (2) (200) 347.

[13] T. Thorsen, R. Roberts, F. Arnold and S. Quake, Phys. Rev. Lett. 86 (18) (2001) 4163.

[14] P. Garstecki, M. J. Fuerstman, H. A. Stone and G. M. Whitesides, Lab Chip 6 (3) (2006) 437.

[15] J. D. Tice, A. D. Lyon and R. F. Ismagilov, Anal. Chim. Acta 507 (1) (2004) 73.

[16] S. van der Graaf, T. Nisisako, C. G. P. H. Schroën, R. G. M. van der Sman, and R. M. Boom, Langmuir 22 (9) (2006) 4144-4152.

[17] H. Gu, M. H. G. Duits and F. Mugele, Int. J. Mol. Sci. 12 (4) (2011) 2572.

[18] L. Sang, Y. Hong and F. Wang, Microfluid. Nanofluidics 6 (5) (2009) 621.

[19] M. De Menech, Phys. Rev. E 73 (3) (2006) 31505.

[20] S. Bashir, J. M. Rees and W. B. Zimmerman, Chem. Eng. Sci. 66 (2011) 4733.

[21] X. Zhao, L. Li, B. Li, J. Zhang and A. Wang, J. Mater. Chem. A 2 (43) (2014) 18281. 